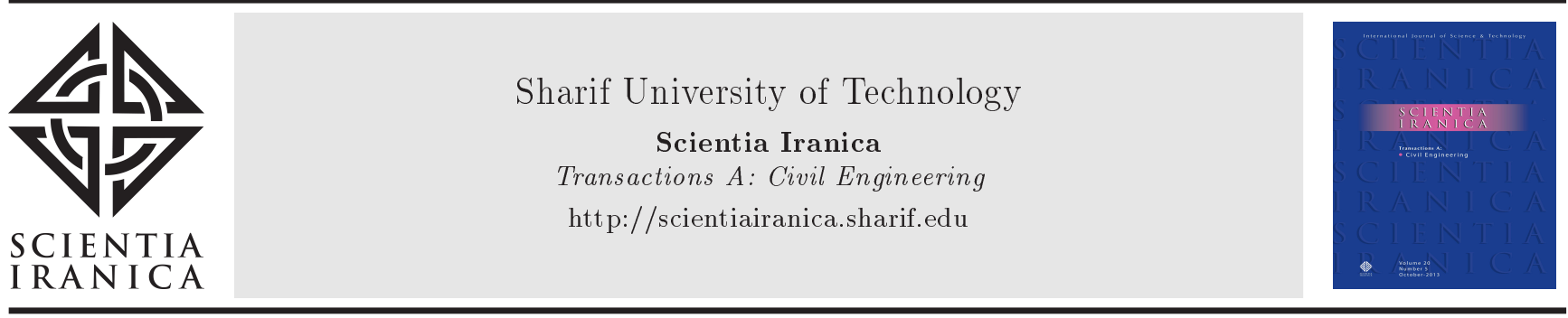

\title{
Determination of energy damping upon impact load in reinforced concrete sandwich plates with different core geometries
}

\author{
S. Savaş ${ }^{a}$, M. Ülker ${ }^{b}$, S. Turgut ${ }^{a}$, and D. Bakır ${ }^{a, *}$ \\ a. Department of Civil Engineering, Faculty of Engineering, Firat University, 23100, Elazı̆ \\ b. Department of Civil Engineering, Faculty of Engineering, Turgut Özal University, 44210, Malatya
}

Received 8 December 2020; received in revised form 9 March 2021; accepted 2 August 2021

\section{KEYWORDS}

Sandwich plate;

Impact load;

Impact test;

Impact effect;

Reinforced concrete.

\begin{abstract}
It can be challenging to analyze Reinforced Concrete (RC) sandwich plates with hollow structures under impact loads in terms of crushing, punching, cracking, and crack trajectories via static and dynamic equations. In the literature, the finite element solutions were provided after determining the behaviors of the materials based on the test results. Therefore, it is required to test the behaviors of RC plates. To this end, the behaviors of sandwich plates under impact loads were experimentally analyzed in this study. The sandwich plates were manufactured by cutting Polyester Foams (PF) into hexagonal prisms, square prisms, I-type, and S-type and installing them inside the RC plates. The manufactured sandwich plates were $27 \%$ lighter than full plates. A weight of $320 \mathrm{~kg}$ declined freely from $2.5 \mathrm{~m}$, and the load was implemented at the center of the plate at a velocity of $7.5 \mathrm{~m} / \mathrm{s}$. Similar implementations were also conducted for filled plates and the maximum displacements were measured in both types of plate tests. The measurements obtained from each test were compared to determine the sandwich plate with the core geometry which provided the highest absorption and the lowest displacement. In the analyses, the S-type core geometry exhibited greater absorption than other core geometries.
\end{abstract}

(C) 2021 Sharif University of Technology. All rights reserved.

\section{Introduction}

The design of Reinforced Concrete (RC) structures in the face of impact load has long been an area of interest for researchers. Most of the early studies in the literature have been conducted on examining the behavior of RC structures exposed to ballistic

*. Corresponding author. Tel.: +90 4242370000/5411

E-mail addresses: ssavas@firat.edu.tr (S. Savaş);

mehmet.ulker@ozal.edu.tr (M. Ülker);

sevalcan@hotmail.com (S.Turgut); dbakir@firat.edu.tr (D. Bakır)

doi: $10.24200 /$ sci.2021.56554.5165 weapons [1]. In addition, a number of variables were used in these experimental studies to examine the behavior of concrete in the face of impact. These variables included the mixing ratios of concrete, reinforcement of concrete with different types of fibers, location and amount of reinforcement, impact velocities and contact surface types of impacting objects, and weight of the impact load.

An experimental study was conducted to investigate the impact behavior of RC plates. Zineddin and Krauthammer [2] used nine $\mathrm{RC}$ plates in three types with dimensions of $90 \times 1524 \times 3353 \mathrm{~mm}$. In their study, the types of specimens were determined by changing the ratio of reinforcement in the concrete. 
The impact mass was determined as $2608 \mathrm{~kg}$, and the drop heights were determined as $152 \mathrm{~mm}, 305 \mathrm{~mm}$, $610 \mathrm{~mm}$, respectively. Based on the results from the analyses, it was determined that the severity of the impact varied depending on the drop height and the location of the steel reinforcement altered the effect of the impact load. Chen and May [3] conducted an experimental study where they subjected RC structures to vertical impact loads. In their study, 18 beams and six plates, four with dimensions of $760 \times 760 \times 76$ $\mathrm{mm}$, and two with dimensions of $2300 \times 2300 \times 150$ $\mathrm{mm}$ dimensions were investigated. In addition, 196.7 $\mathrm{kg}$ and $382 \mathrm{~kg}$ masses were used for the plate. The plates were then subjected to free-falling loads of 8 , 8.7 , and $8.3 \mathrm{~m} / \mathrm{s}$, respectively. The steel reinforcement ratio of the plates was $0.5 \%$. In the beams and plates, the strength values of the concrete cube were 47.3 and $55.7 \mathrm{MPa}$, respectively. The corners of the plates were supported by simple supports that could rotate freely. For the first weight, a steel impact unit with a hemispherical impact contact surface tip of $90 \mathrm{~mm}$ in diameter was chosen. For the second weight, a cylinder with a flat surface of $100 \mathrm{~mm}$ in diameter was selected. As observed, the impact contact surface of the hemispherical unit created a more circular cracking area on the bottom face of the plate compared to the flat unit. Živaljic et al. [4] conducted a study that compared numerical modeling with the experimental data. They employed plates with dimensions of $2000 \times$ $2000 \times 180 \mathrm{~mm}$ in their study. The structure unit that lost $300 \mathrm{~kg}$ in weight with a diameter of $90 \mathrm{~mm}$ and a hemisphere shape with a radius of $507 \mathrm{~mm}$ was chosen. The impact structure declined at a constant impact velocity of $4 \mathrm{~m} / \mathrm{s}$. According to the experiment results, the maximum impact forces were independent of the support conditions. Hummeltenberg et al. [5] conducted different impact tests on concrete plates. They examined the behavior of the RC plates, manufactured from a standard, high-performance, and ultra-high-performance concrete. In their study, 15 specimens with dimensions of $1000 \times 1000 \times 150 \mathrm{~mm}$ were investigated. Steel reinforcement of $10 \mathrm{~mm}$ in diameter was placed on all the plates in both directions with $150 \mathrm{~mm}$ intervals. Six plates were then reinforced by fiber mesh. Plates were supported with simple supports at four corners of the plate and load cells were placed under the supports. While increasing the drop height from 3 to $9 \mathrm{~m}$, the falling velocities increased from 7.7 to $13.3 \mathrm{~m} / \mathrm{s}$. As a result of the tests, all plates with standard concrete and standard steel reinforcement were damaged and punctured. Plates with additional fiber reinforcement were also damaged; however, they were not completely punctured. Mao and Barnett [6] conducted a systematic study on the toughness of Ultra-High Performance Fiber Reinforced Concrete (UHPFRC) to better understand UHPFRC resistance under impact load. Further, UHPFRC beams with different fiber volumes were tested under impact loads at different strain rates. According to the test results, the relationship between the toughness of UHPFRC and strain rate could be clarified. An increasing trend in the strain and toughness rates was observed with increasing fiber volume in the UHPFRC specimens. Furthermore, the fracture resistance of the UHPFRC specimens increased as well. In their study, the effect of fibers of different lengths was examined, and it was reported that the fiber combination could only provide slightly higher toughness for the UHPFRC beam, especially in ranges of high strain rates. Zhao et al. [7] examined the drop-weight test program that was developed to investigate the shear failure modes of large-scale RC beams under impact loads. The test variables examined in the study included transverse reinforcement, beam spacing ratio, impact velocity, and impact mass. The impact and reaction forces at different positions along the beam as well as the displacement and acceleration at the middle point were measured. Measurements were conducted and recorded using a high-resolution camera. Increased transverse reinforcement ratio prevented the specimens from shear fracture. However, the effect of the beam on the earlystage response was negligible.

Kaçaran [8] utilized nine pieces of RC plates with dimensions of $1000 \times 1000 \times 80 \mathrm{~mm}$ to examine the behavior of RC plates under the impact loads and tested them by decreasing weights of the specimens using a specifically prepared test setup. In his study, three different reinforcement ratios and three different impact energies were tested to perform experiments on the specimens. In the experiments, an $84 \mathrm{~kg}$ hammer was dropped on the specimens from $1 \mathrm{~m}, 1.25$ $\mathrm{m}$, and $1.50 \mathrm{~m}$, respectively. Moreover, the collision energies were obtained as $0.824 \mathrm{~kJ}, 1.030 \mathrm{~kJ}$, and $1.236 \mathrm{~kJ}$, respectively. As a result, it was revealed that increasing the weight of reinforcement and impact energy would result in considerable increase in the width of the crack that occurred. In other words, the damage rate for the specimens increased. The width of the cracks that occurred on the specimen that was exposed to the highest energy levels expanded up to 10-15 mm, and a hole was formed in the middle point due to the effect of punching. Based on these datasets, it was concluded that reinforcements should be used in the compression and tensile zones on surfaces exposed to impact loads. Ye et al. [9] investigated the impact behavior of RC beams using Large-Rupture-Strain Fiber-Reinforced Polymer (LRSFRP). The effects of FRP types, load velocities, and using or not using the end anchors on the reinforcement efficiency were also studied. Beams reinforced by LRS-FRP fixed to the end offered greater ductility under static loads compared to carbon fiber-reinforced 
polymer counterparts, and the LRS-FRP reinforcement system fixed at the end significantly reduced the maximum displacement and damage of the reinforced beam under the impact. Tan et al. [10] examined the bending behavior of the embedded RC beams with different polystyrene block alignments. Three beams with dimensions of $1600 \mathrm{~mm} \times 175 \mathrm{~mm} \times 300 \mathrm{~mm}$ were tested under a four-point load setup. These specimens were characterized by three different polystyrene block alignments located below the neutral axis. The first specimen with a single rectangular polystyrene block was used as a reference specimen to assess the gap between the polystyrene blocks and presence of the concrete pillar and middle span on the sides of the beam. Beams failed due to the crushing of concrete on top with large bending cracks. The test result confirmed the effects of the alignment of polystyrene blocks on the beam. The presence of gaps increased the ductility while decreasing the final capacity per unit volume. The presence of mid-span and concrete braces improved the final capacity per unit volume and, yet, reduced ductility. Sun et al. [11] examined the damage and bearing capacities of short RC columns under impact loads. Hammers weighing $400 \mathrm{~kg}$ with drop heights of $0.25 \mathrm{~m}$ and $0.5 \mathrm{~m}$ were dropped onto the RC specimens with dimensions of $300 \times 400 \times 1000$ $\mathrm{mm}$. The impact load tests were conducted using a data processing computer, $5000 \mathrm{kN}$ pressure testing machine, and a data logger equipped with a static 16-channel data acquisition device. The preloading velocity was controlled at $4-6 \mathrm{kN} / \mathrm{s}$, and when the final carrying capacity was reached, the loading velocity was reduced to $0.5-1 \mathrm{kN} / \mathrm{s}$. It was observed in the study that the impact resistance of $\mathrm{RC}$ columns exposed directly to the impact test surfaces was reduced due to corrosion of the reinforcement. Loganaganandan et al. [12] conducted experiments to study the impact response of Glass Fiber Reinforced Polymer (GFRP) strips in reinforced Two-Stage Reinforced Concrete Slabs (TSRCS). Upon reinforcing TSRCS, two different widths of $50 \mathrm{~mm}$ and $75 \mathrm{~mm}$ GFRP strips were used vertically and obliquely in one and two directions, respectively. In general, nine TSRCS specimens with dimensions of $1000 \times 1000 \times 60 \mathrm{~mm}$ were manufactured. Then, the tests were conducted with a $55 \mathrm{~kg}$ steel cylinder falling from a height of $3000 \mathrm{~mm}$ on the center point of the specimens. The operating parameters were also analyzed to evaluate the impact response of the TSRCS including impact load, acceleration, damaged area (upper and lower face), damage area ratio, damage volume ratio, and damage pattern. The results revealed that the plates reinforced by $75 \mathrm{~mm}$ GFRP strips were more effective in mitigating the damage volume ratio than those reinforced by $50 \mathrm{~mm}$ GFRP strips.

Khamies and Medhlom [13] evaluated the dy- namic behavior of RC slabs, slab thickness, rebar material, and reinforcement arrangement as well as the effect of falling mass. To conduct experimental analysis, the specimens reinforced by steel bars and carbon fiber-reinforced polymers were manufactured. In addition, the specimens were manufactured at two different dimensions of $1550 \times 1550 \times 120 \mathrm{~mm}$ and $1550 \times 1550 \times 150 \mathrm{~mm}$. Steel weights ranging from 50 to $150 \mathrm{~kg}$ declined in a free fall from $2.5 \mathrm{~m}$. The experimental results of the study demonstrated that the shear properties of slabs had a significant effect on their general behavior. Furthermore, CRFP provided high strength rates and corrosion resistance. Accordingly, the researchers stated that CFRP was a favorable material for reinforcement purposes. Tran et al. [14] investigated the impact response of geopolymer concrete (GPC) beams reinforced by different types of fibers and Basalt Fiber Reinforced Polymer (BFRP) bars. Four GPC beams reinforced by steel fibers or synthetic fibers and two control beams made of GPC and Ordinary Portland Cement (OPC) without fiber reinforcement were manufactured. BFRP rods and stirrups were used for longitudinal and transverse reinforcements, respectively. The volume ratios of the fibers used in the study ranged from $0 \%$ to $0.5 \%$ in the concrete mixtures. All beams were tested under the impact loads of the drop weights. Following the impact tests, the damaged beams were loaded separately under three-point bending tests to analyze the remaining strength. Experimental results revealed that the presence of the fibers reduced damage in the impact zone and mitigated the damages in the concrete lining at the base of the beams. Batarlar [15] carried out a series of experiments to evaluate the behavior of RC plates in face of impact load. To this end, six plate specimens were designed in the experiment, and the effects of static and impact loads on the RC plates were examined. The specimens were cast as three identical pairs, all with dimensions of $2015 \times 2015 \times 150 \mathrm{~mm}$ and reinforcement thickness of $\varnothing 8 \mathrm{~mm}$. The reinforcement intervals were 100,150 , and $200 \mathrm{~mm}$, respectively. The reaction values of the supports were read from the 20 load cells placed at the bottom of the plate with five load cells on each side. The load was applied using a circular steel unit of $200 \mathrm{~mm}$ in diameter. The dropped weights were measured at $210 \mathrm{~kg}$ and 320 $\mathrm{kg}$. At the end of the study, it was observed that the reaction forces measured under impact loads were higher than those of the static loads. In the present study, the RC plate dimensions and impact loads applied to the plates in the study of Batarlar [15] were regarded as a reference. For the plates manufactured for the tests, sandwich plate designs were made of Polyester Foams (PFs) with different geometries and without load-bearing qualities. These impact loads were implemented on these $\mathrm{RC}$ plates manufactured by 
the new technique, and the ratios of impact absorption between filled plates and sandwich plates were assessed.

\section{Experimental setup}

\subsection{Specimen}

The testing stand was manufactured by high steel, I200 (St52), profile with high strength moment used for prevention of bending due to the moment that would occur on the plate during the impact. The RC plate was supported semi-statically while the reactions of the supports were measured by loads of cells placed at each corner point of the steel stand (Figure 1).

While preparing the weights used for the experiment, an empty steel bucket with a $200 \mathrm{~mm}$ diameter flat impact surface was filled with concrete and iron pieces to achieve a weight of $320 \mathrm{~kg}$ (Figure 2). The load dropped from $2.5 \mathrm{~m}$ with free fall at the middle point of the plate.

Two data collection devices were used in the

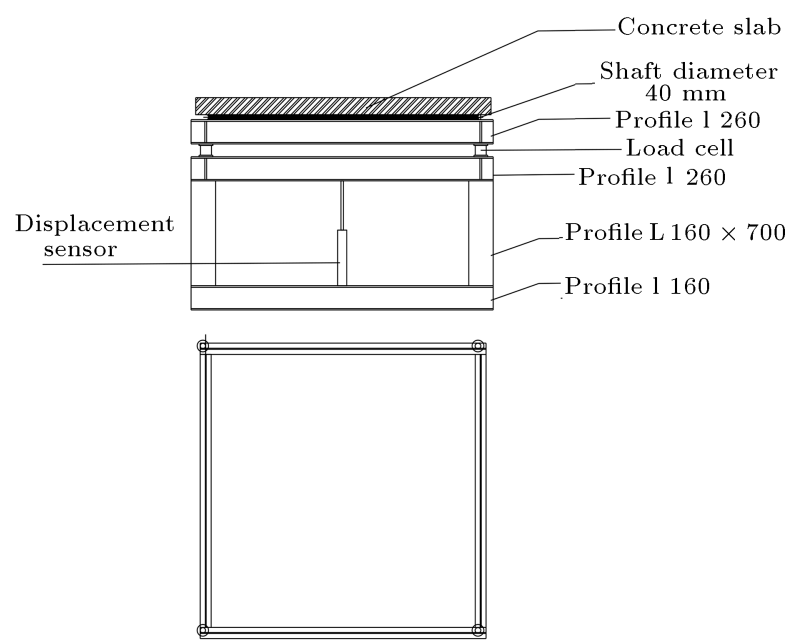

Figure 1. The table manufactured for the test setup.
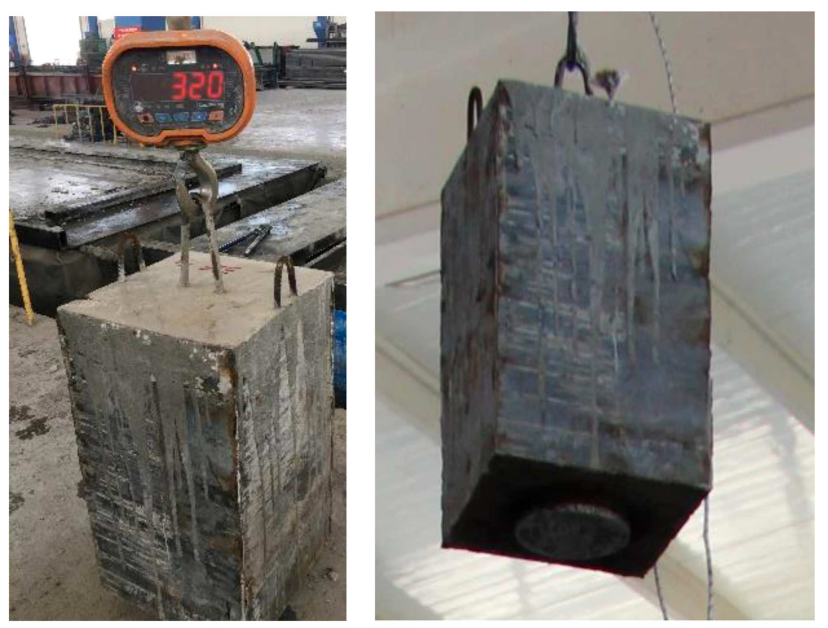

Figure 2. The weights used for the experiment. experiment. The first one was the TESTBOX1001. Four load cells, each of which had a capacity to measure $100 \mathrm{kN}$, were connected to this device and the loads on the support points were measured. The other data collection tool was the OROS-OR-36 data collection tool, which was connected to a laser displacement meter. A laser displacement meter branded as RIFTEK RF603 model was connected to this device. Additionally, an image processing method was used in the study. For this, video footages $(1 / 1000 \mathrm{fps})$ were recorded for the displacement at the time of impact to conduct image processing via Huawei P30 mobile phone with 960 fps slow-motion feature.

\subsection{Slabs}

Six different types of concrete plates and three identical specimens for each type, constituting a total of $18 \mathrm{RC}$ plates, were manufactured in the test process. Three of these plates were filled plates with $2000 \times 2000 \times 150 \mathrm{~mm}$ dimensions, while 12 of them were sandwich plates featuring different core geometries with $2000 \times 2000 \times 150$ mm dimensions (Figures 3 and 4). Moreover, 3 filled plates with $2000 \times 2000 \times 110 \mathrm{~mm}$ dimensions were manufactured with the same volume as the sandwich plates.

The dimensions of the polystyrene foams placed in the molds before concrete casting in the manufacturing process of the sandwich plates are presented in Table 1. While determining these dimensions, much attention

Table 1. Abbreviations used for the specimen in the study.

\begin{tabular}{|c|c|c|c|}
\hline $\begin{array}{l}\text { Specimen } \\
\text { name }\end{array}$ & $\begin{array}{l}\text { Specimen } \\
\text { type }\end{array}$ & $\begin{array}{l}\text { Specimen } \\
\text { no. }\end{array}$ & $\begin{array}{l}\text { Specimen } \\
\text { code }\end{array}$ \\
\hline \multirow{6}{*}{$\begin{array}{l}\text { Reinforced concrete } \\
\text { sandwich plate }\end{array}$} & Hexagon & & $\begin{array}{l}\text { RCSP-H1 } \\
\text { RCSP-H2 } \\
\text { RCSP-H3 }\end{array}$ \\
\hline & $\mathrm{S}$ & & $\begin{array}{l}\text { RCSP-S1 } \\
\text { RCSP-S2 } \\
\text { RCSP-S3 }\end{array}$ \\
\hline & Squar & $1,2,3$ & $\begin{array}{l}\text { RCSP-Sq1 } \\
\text { RCSP-Sq2 } \\
\text { RCSP-Sq3 }\end{array}$ \\
\hline & Beam & & $\begin{array}{l}\text { RCSP-B1 } \\
\text { RCSP-B2 } \\
\text { RCSP-B3 }\end{array}$ \\
\hline & Rectangle & & $\begin{array}{l}\text { RCSP-R1 } \\
\text { RCSP-R2 } \\
\text { RCSP-R3 }\end{array}$ \\
\hline & Rectangl 11e & & $\begin{array}{l}\text { RCSP11-R1 } \\
\text { RCSP11-R2 } \\
\text { RCSP11-R3 }\end{array}$ \\
\hline
\end{tabular}




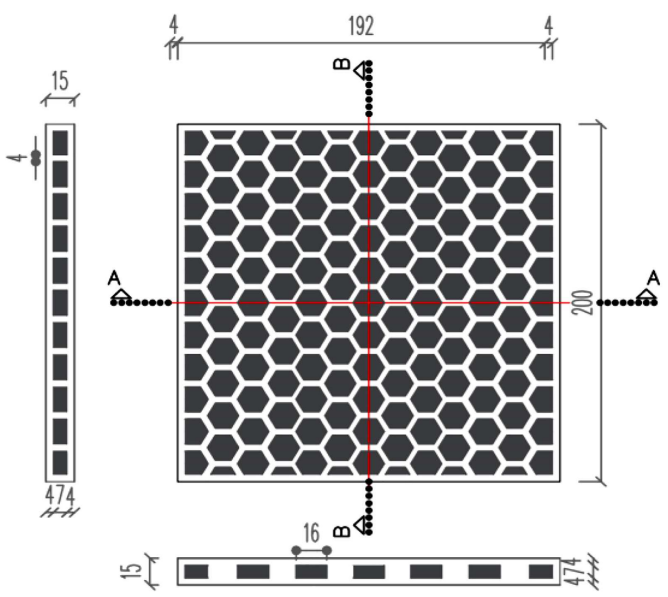

(a)

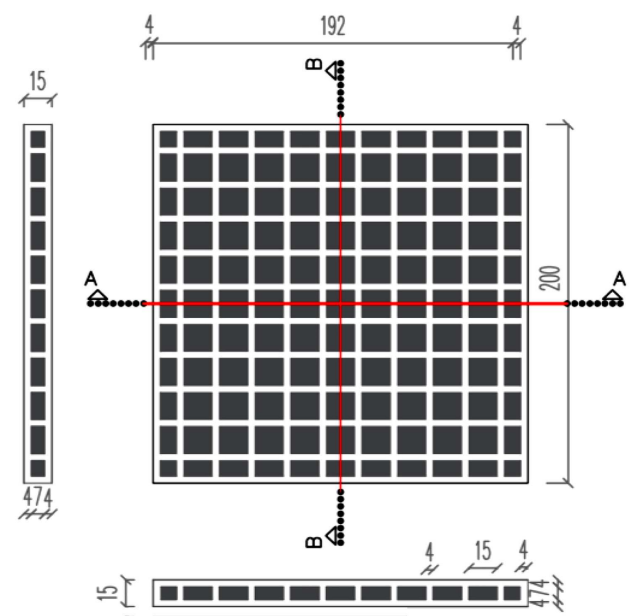

(b)

Figure 3. (a) Sandwich plates with hexagonal spaces (RCSP-H-1,2,3). (b) Sandwich plates with square spaces (RCSP-Sq-1,2,3).

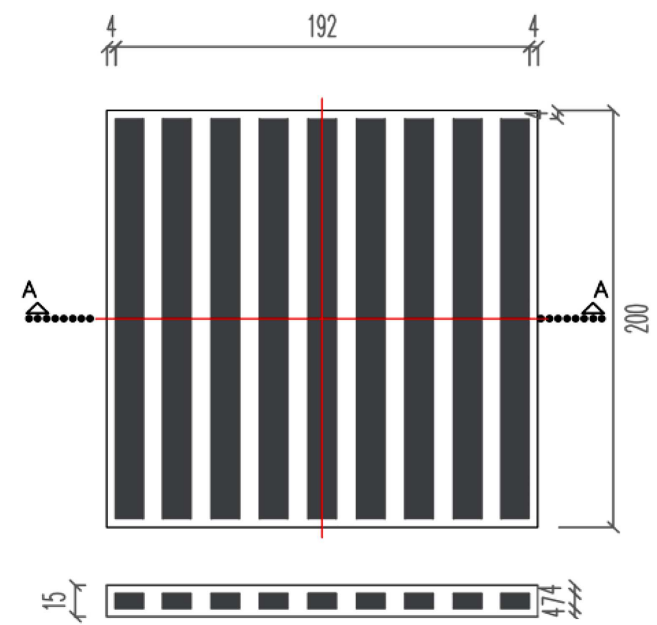

(a)

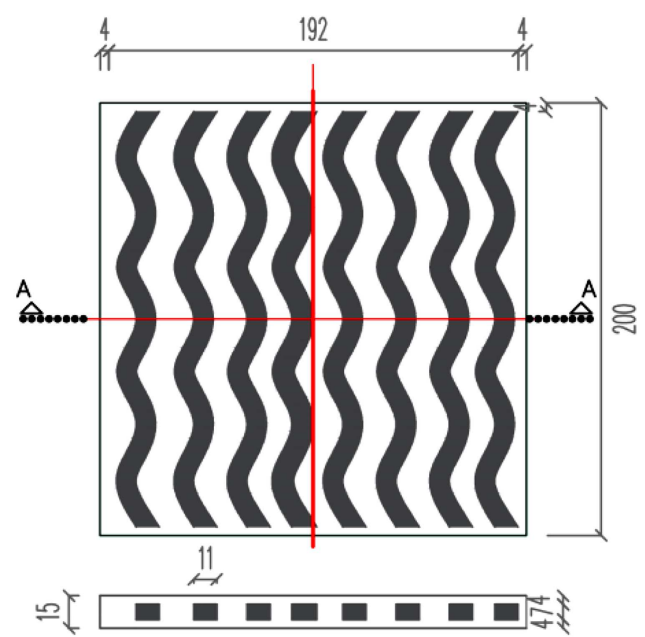

(b)

Figure 4. (a) Sandwich plates with beam spaces (RCSP-B-1,2,3). (b) Sandwich plates with S spaces (RCSP-S-1,2,3).

was paid to ensure that the volumes of all the sandwich plates would be equal. These volumes are presented in Table 2. As a result, creating a core structure reduces the weights of the panels by $26.67 \%$ on average.

Standard steel wire mesh, $\varnothing$ 131/131(DIN-
GRADE500A), was used for the reinforcement of the plates (Figure 5). The quanitites of wire meshes were kept constant in all the specimens, and four layers (two layers at the bottom and two layers at the top) were installed for each plate. While installing steel meshes,

Table 2. Descriptive data.

\begin{tabular}{|c|c|c|c|c|}
\hline $\begin{array}{l}\text { Specimen } \\
\text { code }\end{array}$ & $\begin{array}{c}\text { Dimensions of the } \\
\text { specimen } \\
\text { (width/length/height }(\mathrm{cm}))\end{array}$ & $\begin{array}{r}\text { PF shapes a } \\
\text { length of the ec } \\
\text { (Height: } 7\end{array}$ & he & $\begin{array}{l}\text { Concrete volume } \\
\qquad\left(\mathbf{m}^{3}\right)\end{array}$ \\
\hline RCSP-H-1,2,3 & $200 \times 200 \times 15$ & Regular hexagon & 6 & 0.44 \\
\hline RCSP-S-1,2,3 & $200 \times 200 \times 15$ & S shaped & 11 & 0.44 \\
\hline RCSP-Sq-1,2,3 & $200 \times 200 \times 15$ & Square & 15 & 0.44 \\
\hline RCSP-B-1,2,3 & $200 \times 200 \times 15$ & Rectangle & 15 & 0.44 \\
\hline RCSP-R-1,2,3 & $200 \times 200 \times 15$ & - & & 0.60 \\
\hline RCSP-R11-1,2,3 & $200 \times 200 \times 11$ & - & & 0.44 \\
\hline
\end{tabular}




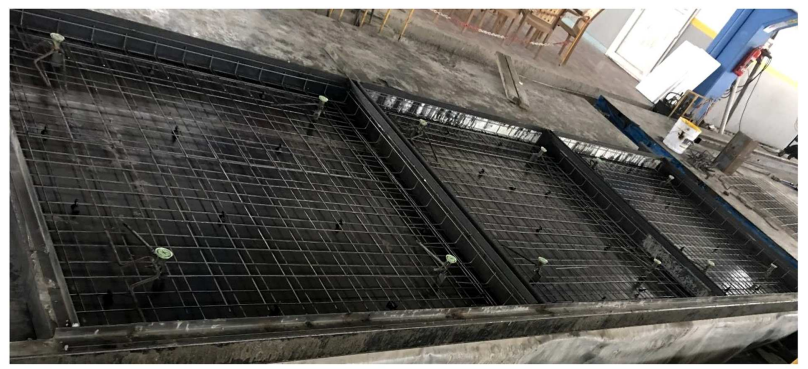

Figure 5. Bottom and top layer placement of wire meshes.

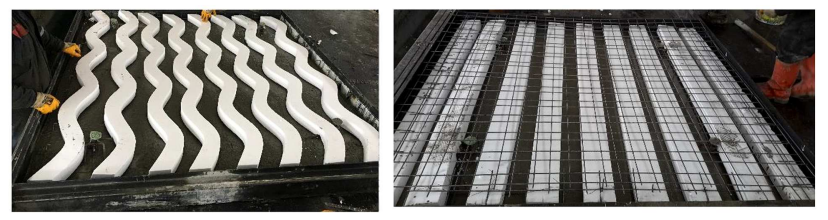

Figure 6. Placement of polystyrene foams and steel wire meshes for RCSP-S and RCSP-B.
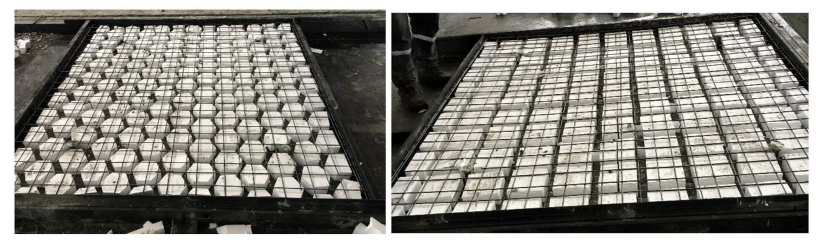

Figure 7. Placement of polystyrene foams and top wire meshes RCSP-H and RCSP-Sq.

two layers were installed and staggered and it was ensured that the reinforcements would not overlap.

PFs were prepared by cutting them in desired shapes with a CNC cutting system which operated with heat. The heights of the PFs were $7 \mathrm{~cm}$ for the geometries of all the specimens. The width of the polyurethane material was chosen to be smaller than that of the impact zone. Here, the aim was to ensure that the impact would be transmitted to a lower part of the plate by punching the upper part of the plate (Figures 6 and 7 ).

\subsection{Material properties}

The type of wire mesh used in the tests was Q 131/131 and four layers were installed: two at the bottom and two on the top. The concrete mixture ratios used in plate manufacturing are given in Table 3 . These results are presented in Table 4 . Two specimens were taken from the concrete mixture and subjected to 7 - and 28 day strength tests (Table 5).

Table 3. Steel wire mesh.

\begin{tabular}{ll}
\hline Reinforcement range & $150 \mathrm{~m}$ \\
Reinforcement diameter & $5.0 \mathrm{~mm}$ \\
Reinforcement cross-sectional area & $1.31 \mathrm{~m}^{2}$ \\
Bidirectional reinforcement rate & $0.35 \%$ \\
\hline
\end{tabular}

Table 4. Concrete mixing ratios.

\begin{tabular}{ll}
\hline Cement & $16 \%$ \\
Aggregate (7-14 mm diameter) & $35.40 \%$ \\
Aggregate (3-9 mm diameter) & $4.40 \%$ \\
Sand & $37.60 \%$ \\
Water & $6.40 \%$ \\
Additive & $0.20 \%$ \\
\hline
\end{tabular}

Table 5. Results of concrete specimens.

\begin{tabular}{|c|c|c|}
\hline $\begin{array}{l}\text { Specimen } \\
\text { code }\end{array}$ & $\begin{array}{l}\text { Casting date } \\
(\mathrm{dd} / \mathrm{mm} / \mathrm{yy})\end{array}$ & $\begin{array}{l}\text { 28-day compressive } \\
\text { strength }\left(\mathrm{N} / \mathrm{mm}^{2}\right)\end{array}$ \\
\hline RCSP-H-1 & 02.04 .19 & 53.19 \\
\hline RCSP-H-2 & 02.04 .19 & 53.19 \\
\hline RCSP-H-3 & 02.04 .19 & 53.19 \\
\hline RCSP-B-1 & 27.03 .19 & 59.33 \\
\hline RCSP-B-2 & 28.03 .19 & 42.99 \\
\hline RCSP-B-3 & 29.03 .19 & 53.29 \\
\hline RCSP-R-1 & 27.03 .19 & 59.33 \\
\hline RCSP-R-2 & 27.03 .19 & 59.33 \\
\hline RCSP-R-3 & 27.03 .19 & 59.33 \\
\hline RCSP-R11-1 & 03.04 .19 & 45.11 \\
\hline RCSP-R11-2 & 03.04 .19 & 45.11 \\
\hline RCSP-R11-3 & 03.04 .19 & 45.11 \\
\hline RCSP-Sq-1 & 30.03 .19 & 55.15 \\
\hline RCSP-Sq-2 & 30.03 .19 & 55.15 \\
\hline RCSP-Sq-3 & 02.04 .19 & 53.19 \\
\hline RCSP-S-1 & 29.03 .19 & 53.29 \\
\hline RCSP-S-2 & 30.03 .19 & 55.15 \\
\hline RCSP-S-3 & 30.03 .19 & 55.15 \\
\hline
\end{tabular}

\section{Results and discussion}

\subsection{Behavior of specimens during the experiment and the collected data}

3.1.1. Sandwich plate specimens with a hexagonal core shape (RCSP-H1 RCSP-H2, RCSP-H3)

The concrete used in the specimen with hexagonal spaces had a width of $4 \mathrm{~cm}$ and a height of $7 \mathrm{~cm}$. The inner diameter of the circle of the hexagonal space was $16 \mathrm{~cm}$ and the impact hammer diameter was designed to be less than $20 \mathrm{~cm}$ at the moment of falling. Three specimens were cast and the impact tests were conducted after reaching the 28th day strength. Cracks appeared on a $76 \mathrm{~cm}$ diameter area from the center of the plate (Figure 8). In the first specimen, the upper collapse in the impact zone was measured at $1.6 \mathrm{~cm}$ (Figure 9). A total reaction of $33 \mathrm{kN}$ in the load cells placed at the corner points was measured.

\subsubsection{Filled plate specimens with a thickness of 11 cm (RCSP-R11-1, RCSP-R11-2, and $R C S P-R 11-3)$}

The objective of forming the RCSP-R11 specimen was to form filled plates with the same volume of concrete as the sandwich plates and then, to make a comparative 


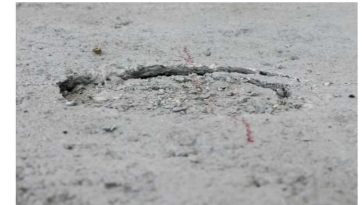

(a)

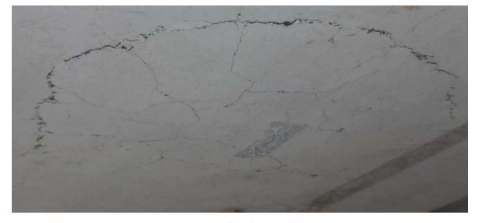

(b)
Figure 8. (a) Surface damage at the top. (b) Surface damage at the bottom.

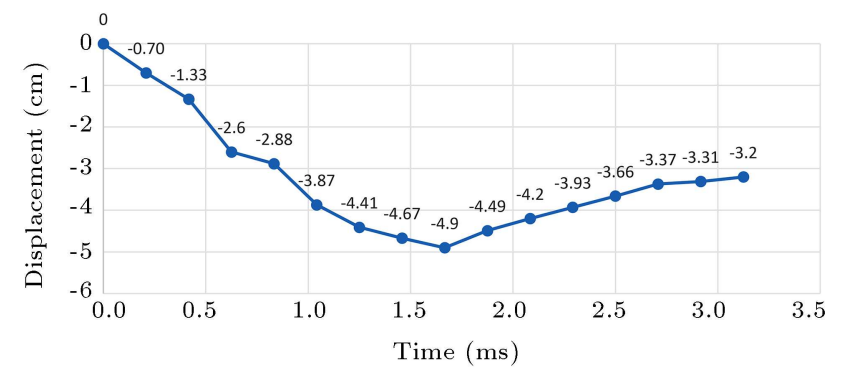

Figure 9. Displacement-time graph (RCSP-H).

study. For this purpose, plates with a thickness of $11 \mathrm{~cm}$ were cast. Three specimens were cast and the impact tests were conducted after reaching the 28th day strength. Cracks appeared on the area with a 62 $\mathrm{cm}$ diameter from the center of the plate and regional spills were detected at the border of the crack on the plate (Figure 10). In the first specimen, the upper collapse in the impact zone was measured at $0.3 \mathrm{~cm}$ (Figure 11). A total reaction of $20 \mathrm{kN}$ was measured in the load cells placed at the corner points.

\subsubsection{Filled plate specimen with a thickness of $15 \mathrm{~cm}$ (RCSP-R-1, RCSP-R-2, and RCSP-R-3)}

This study aims to compare the plates tested in the literature with the manufactured plates filled with equal values of concrete. For this purpose, $15 \mathrm{~cm}$-thick

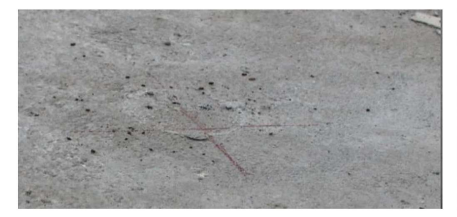

(a)

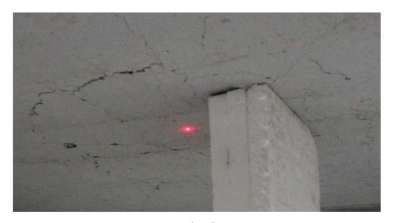

(b)
Figure 10. (a) RCSP-R11-3 surface damage at the top.

(b) Surface damage at the bottom.

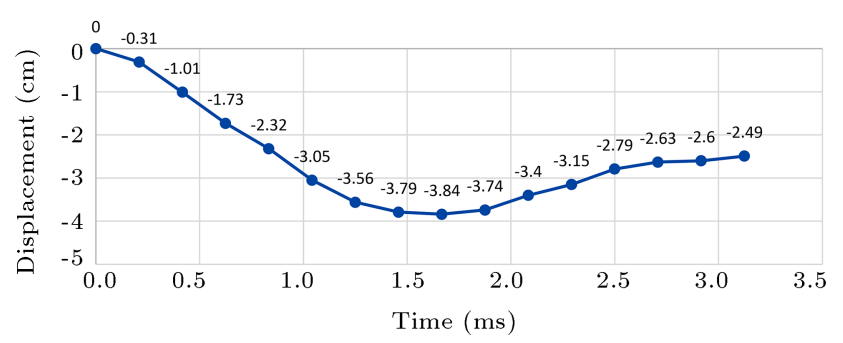

Figure 11. Displacement-time graph (RCSP-R11).

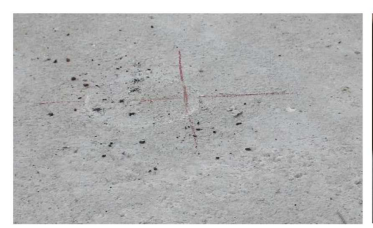

(a)

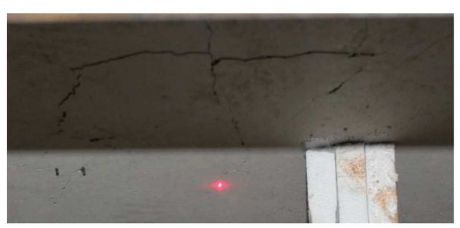

(b)
Figure 12. (a) RCSP-R-3 surface damage at the top. (b) Surface damage at the bottom.

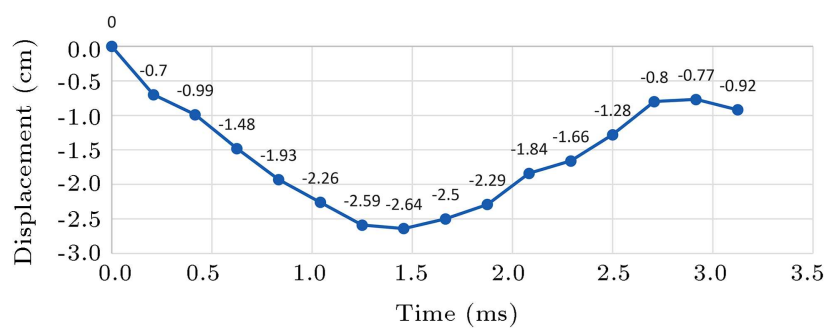

Figure 13. Displacement-time graph (RCSP-R).

plates were cast. Three specimens were cast and the impact tests were conducted after reaching the 28th day strength. Cracks were observed in the area with a diameter of $87 \mathrm{~cm}$ from the center of the plate, and small amounts of regional spills in the plate at the border of the crack were observed (Figure 12). In the first specimen, the upper collapse in the impact zone was measured at $0.3 \mathrm{~cm}$ (Figure 13). A total reaction of $55 \mathrm{kN}$ was measured in the load cells placed at the corner points.

\subsubsection{Sandwich plate specimen with a square core shape (RCSP-Sq-1, RCSP-Sq-2, and $R C S P-S q-3)$}

In this paper, the width of the concrete between the square spaces was $4 \mathrm{~cm}$ and its height was $7 \mathrm{~cm}$. The square spaces were $15 \times 15 \mathrm{~cm}$ in dimension and the diameter of the impact hammer was designed to be less than $20 \mathrm{~cm}$ at the moment of falling. Three specimens were cast, and the impact tests were conducted after reaching the 28th day strength. Cracks appeared on an area with the averaged $76 \mathrm{~cm}$ diameter from the center of the plate and no major destruction in the concrete was observed (Figure 14). In the first specimen, the upper collapse in the impact zone was measured at

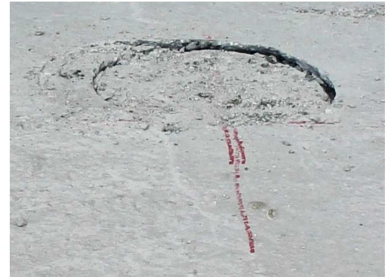

(a)

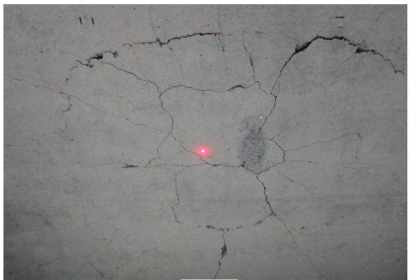

(b)
Figure 14. (a) RCSP-Sq-1 surface damage at the top. (b) Surface damage at the bottom. 


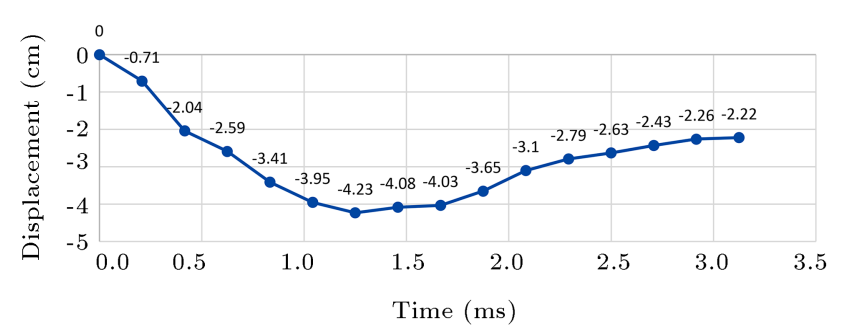

Figure 15. Displacement-time graph (RCSP-Sq).

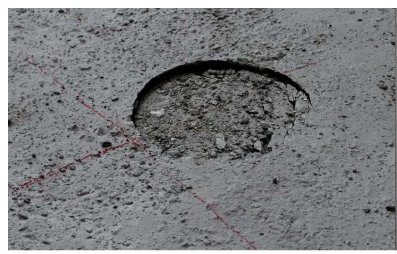

(a)

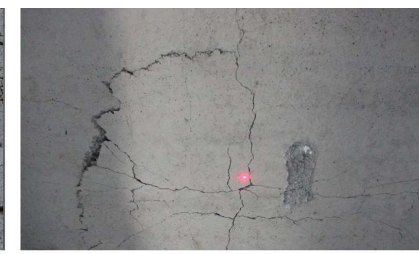

(b)
Figure 16. (a) RCSP-B-3 surface damage at the top. (b) Surface damage at the bottom.

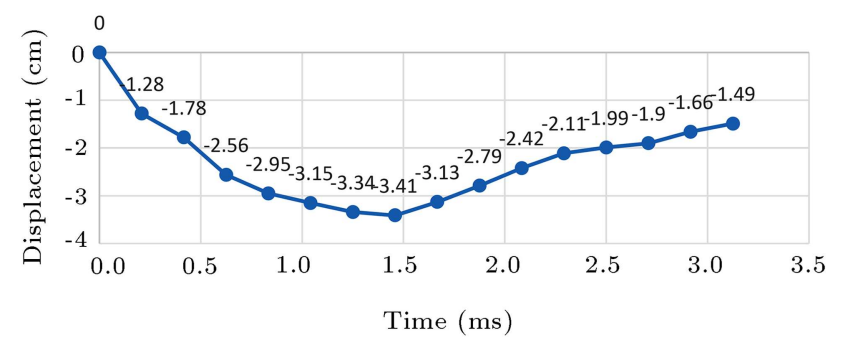

Figure 17. Displacement-time graph (RCSP-B).

$1.1 \mathrm{~cm}$ (Figure 15). A total reaction of $26 \mathrm{kN}$ was measured in the load cells placed at corner points.

\subsubsection{The sandwich plate specimen with vertical rectangular bar core shape (RCSP-B-1, $R C S P-B-2$, and $R C S P-B-3)$}

In this study, the width of the concrete between the longitudinal rectangular prism-shaped spaces was $4 \mathrm{~cm}$ and its height was $7 \mathrm{~cm}$. The width of the rectangular space was $16 \mathrm{~cm}$ and the diameter of the impact hammer was designed to be less than $20 \mathrm{~cm}$ at the time of falling. Three specimens were cast and the impact tests were conducted after reaching the 28 th day strength. Cracks were observed in the $82 \mathrm{~cm}$ diameter area from the center of the plate and no major destructions were observed in the concrete (Figure 16). In the first specimen, the upper depression in the impact zone was measured to be $0.4 \mathrm{~cm}$ (Figure 17). A total reaction of $22 \mathrm{kN}$ was measured in the load cells placed at the corner points.

\subsubsection{The sandwich plate specimens with the vertical direction of $S$-shaped rectangular bar core (RCSP-S-1, RCSP-S-2, and RCSP-S-3)}

In this research, the width of the concrete between the longitudinal rectangular prism-shaped spaces was

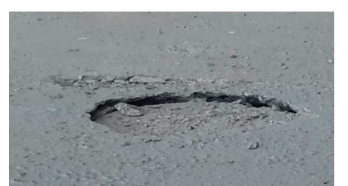

(a)

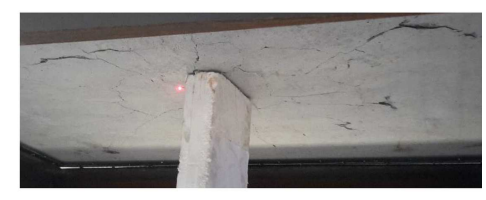

(b)
Figure 18. (a) BSPS3 surface damage at the top. (b) Surface damage at the bottom.

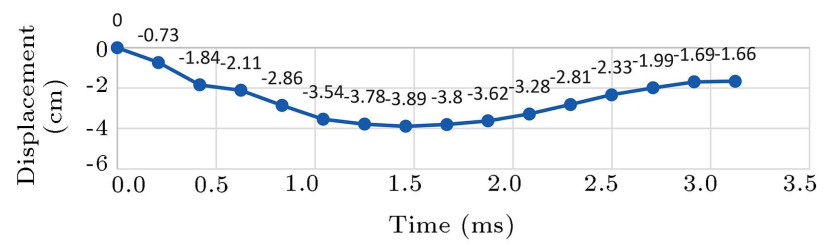

Figure 19. Displacement-time graph (BSPS1).

$4 \mathrm{~cm}$ and its height was $7 \mathrm{~cm}$. The width of the rectangular space was $16 \mathrm{~cm}$ and the diameter of the impact hammer was designed to be less than $20 \mathrm{~cm}$ at the time of falling. Three specimens were cast and the impact tests were conducted after reaching the 28th day strength. Cracks appeared on an area with the averaged $78 \mathrm{~cm}$ diameter from the center of the plate and no major destructions in the concrete were observed (Figure 18). In the case of the first specimen, the upper collapse in the impact zone was measured at $1.3 \mathrm{~cm}$ (Figure 19). A total reaction of 24 $\mathrm{kN}$ was measured in the load cells placed at the corner points. The data obtained from the tests are presented in Table 6 .

\section{Conclusion}

Impact load is not a type of load to which structures are frequently exposed. However, it should be taken into account in barrier designs to prevent damages that occur as a result of rockfalls from slopes and for the safety of vehicles on highways. To ensure that the experimental results reflected the reality of finite element models created by researchers, suitable arrangements were conducted according to test results. However, when the dimensions changed, the results with the same accuracy could not be obtained. Therefore, it is absolutely necessary to conduct impact tests before designing the structures that might be exposed to impact loads with various materials and at every size. Reinforced Concrete (RC) sandwich plates are a novel design and have not been tested under impact loads. Therefore, their significance to energy absorption is not known comprehensively. Therefore, this study aims to reduce the weight of $\mathrm{RC}$ plates under designed impact loads. Accordingly, the behaviors of concrete sandwich plates that are exposed to impact loads were investigated. For this purpose, the impact test results 
Table 6. Data obtained from the tests conducted on the specimens.

\begin{tabular}{|c|c|c|c|c|c|c|c|c|}
\hline \multirow{2}{*}{ Specimen code } & \multirow{2}{*}{$\begin{array}{c}\text { Compressive } \\
\text { strength of } \\
\text { cube specimen } \\
\text { at the } 28 \text { th-day } \\
\left(\mathrm{N} / \mathrm{mm}^{2}\right)\end{array}$} & \multicolumn{5}{|c|}{ Load cell readings $k N$} & \multirow{2}{*}{$\begin{array}{c}\text { Crack } \\
\text { measurement } \\
(\mathrm{cm})\end{array}$} & \multirow{2}{*}{$\begin{array}{c}\text { Collapse } \\
\text { on the top } \\
\text { surface } \\
(\mathrm{cm})\end{array}$} \\
\hline & & P1 & P2 & P3 & $\mathbf{P 4}$ & Total & & \\
\hline RCSP-H-1 & 53.19 & 8.84 & 7.66 & 8.30 & 8.40 & 33 & 76 & 1.6 \\
\hline RCSP-H-2 & 53.19 & 5.73 & 5.82 & 5.59 & 5.67 & 23 & 79 & 2.5 \\
\hline RCSP-H-3 & 53.19 & 12.86 & 12.85 & 14.47 & 14.49 & 55 & 77 & 1.3 \\
\hline RCSP-B-1 & 59.33 & 4.77 & 6.73 & 5.26 & 5.63 & 22 & 83 & 0.4 \\
\hline RCSP-B-2 & 42.99 & 14.54 & 12.08 & 12.04 & 12.92 & 52 & 82 & 1.5 \\
\hline RCSP-B-3 & 53.29 & 13.06 & 10.67 & 13.59 & 12.85 & 50 & 90 & 1.1 \\
\hline RCSP-R-1 & 59.33 & 11.33 & 14.88 & 12.66 & 15.72 & 55 & 87 & 0.3 \\
\hline RCSP-R-2 & 59.33 & 16.31 & 12.60 & 16.18 & 15.62 & 61 & 87 & 0.4 \\
\hline RCSP-R-3 & 59.33 & 12.71 & 11.49 & 12.97 & 12.64 & 50 & 83 & 0 \\
\hline RCSP-R11-1 & 45.11 & 4.00 & 6.03 & 4.43 & 5.72 & 20 & 62 & 0.3 \\
\hline RCSP-R11-2 & 45.11 & 12.08 & 13.67 & 14.94 & 15.09 & 56 & 61 & 0.8 \\
\hline RCSP-R11-3 & 45.11 & 11.22 & 12.91 & 13.59 & 14.95 & 53 & 62 & 0.3 \\
\hline RCSP-Sq-1 & 55.15 & 4.73 & 6.59 & 6.90 & 8.16 & 26 & 76 & 1.1 \\
\hline RCSP-Sq-2 & 55.15 & 6.87 & 6.28 & 5.89 & 7.94 & 27 & 83 & 1.4 \\
\hline RCSP-Sq-3 & 53.19 & 5.63 & 7.77 & 5.17 & 6.94 & 26 & 93 & 1 \\
\hline RCSP-S-1 & 53.29 & 5.01 & 6.42 & 7.82 & 4.98 & 24 & 78 & 1.3 \\
\hline RCSP-S-2 & 55.15 & 4.64 & 5.61 & 5.33 & 4.53 & 20 & 82 & 1.3 \\
\hline RCSP-S-3 & 55.15 & 14.27 & 13.46 & 15.11 & 15.25 & 58 & 74 & 1.2 \\
\hline
\end{tabular}

of sandwich plates with four different core geometries and filled RC slabs were compared.

As a result of the impact tests, the displacements that occurred on the lower and middle points of the specimens and the loads that were applied to the supports were measured. The measured data were compared with the findings obtained through the tests of Batarlar (2013) [15] for the filled plate specimens. Although the subject of support reactions is common in the literature, the results of the current study yielded much lower values than those in the literature. In previous studies in the literature, $1000 \mathrm{kN}$ support reaction and $3 \mathrm{~cm}$ mid-plate displacements occurred as a result of a load created by a weight of $320 \mathrm{~kg}$ dropping from $2.5 \mathrm{~m}$. In our study, the plate was installed on a square frame made of steel profiles with high-strength moments. As a result of the impact, the total values were read from the load cells placed at the corner points of the frame. The numerical value reached up to $60 \mathrm{kN}$. The results indicated that it would be more accurate to collect the operation system of the load cells on four points rather than to spread it across the surface. Theoretically, since the impact is absorbed as much as the displacement in the system, the support reactions should be low as well. In previous studies, the collapses on the surfaces associated with the impact were not measured. In our study, the amounts of absorption were investigated by measuring displacement on the upper surface of the plate. According to the measurements, it was observed that the higher the collapse amounts, the lower the support reaction and the lower the values of displacement in the middle of the plate.

\section{Acknowledgements}

This study was conducted with the help of the Firat University Scientific Research Projects Units (FUBAP Project No: MF.19.09). We are grateful to their financial and technical support.

\section{References}

1. Kennedy, R.P. "A review of procedures for the analysis and design of concrete structures to resist missile impact effects", Nucl. Eng. Des., 37, pp. 183-203 (1976).

2. Zineddin, M. and Krauthammer, T. "Dynamic response and behavior of reinforced concrete slabs under 
impact loading", Int. J. Impact Eng., 34(9), pp. 15171534 (2007).

3. Chen, Y. and May, I.M. "Reinforced concrete members under drop-weight impacts", Proc. Inst. Civ. Eng. Struct. Build., 162(1), pp. 45-56 (2009).

4. Živaljić, N., Nikolić, Z., Smoljanović, H., and Munjiza, A. "Numerical simulation of reinforced concrete structures under impact loading", Materwiss. Werksttech., 50(5), pp. 599-610 (2019).

5. Hummeltenberg, A., Beckmann, B., Weber, T., and Curbach, M. "Investigation of concrete slabs under impact load", Appl. Mech. Mater., 82, pp. 398-403 (2011).

6. Mao, L. and Barnett, S.J. "International journal of impact engineering investigation of toughness of ultra high performance fi bre reinforced concrete (UHPFRC) beam under impact loading", Int. J. Impact Eng., 99, pp. 26-38 (2017).

7. Zhao, D.B., Yi, W.J., and Kunnath, S.K., "Shear mechanisms in reinforced concrete beams under impact loading", J. Struct. Eng., 143(9), p. 04017089 (2017).

8. Kaçaran, G. "Experimental investigation of the collision behavior of reinforced concrete floors", Eskişehir Osmangazi Univ. master thesis, p. 121 (2018).

9. Ye, Z., Zhao, D., Sui, L., Huang, Z., and Zhou, $\mathrm{X}$. "Behaviors of large-rupture-strain fiber-reinforced polymer strengthened reinforced concrete beams under static and impact loads", Front. Mater., 7 (November), pp. 1-17 (2020).

10. Tan, D., Lung, T., and Hua, L.J. "Flexural behaviour of reinforced concrete beam embedded with different alignment of polystyrene", pp. 13-18 (2020).

11. Sun, G., Zhang, Y., Tian, Y., Bo, L., Shen, J., and Shi, J. "Investigation of residual bearing capacity of corroded reinforced concrete short columns under impact load based on nondestructive testing", Math. Probl. Eng., 2020 (2020).

12. Loganaganandan, M., Murali, G., and Parasuraman, M. "Experimental study on GFRP strips strengthened new two stage concrete slabs under falling mass collisions", 25, pp. 235-244 (2021).

13. Khamies, T. and Medhlom, M.K. "Effect of impact load on the performance of concrete", Journal of
Engineering and Sustainable Development (JEASD), 25(01), pp. 68-79 (2021).

14. Tran, T.T., Pham, T.M., Huang, Z., Chen, W., and Hao, H. "Impact response of fibre reinforced geopolymer concrete beams with BFRP bars and stirrups", Eng. Struct., 231 (January), p. 111785 (2021).

15. Batarlar, T. "Behavior of reinforced concrete slabs subjected to impact loads", Özmir Inst. Technol. thesis (2013).

\section{Biographies}

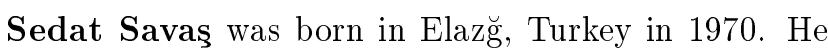
received his BS from the Firat University in 1993, his MS from Firat University in 1995, and his PhD from Firat University in 2002. He is currently at the University of Firat. The author continues to work on various projects on blasting and impact effects.

Mehmet Ülker was born in Malatya, Turkey in 1956. He received his $\mathrm{PhD}$ from Firat University in 1989. He is currently at the Turgut Ozal University. The author has been working with the title of professor since 2001 . He has several studies on mechanics, optimization, blasting and impact effects of structures.

Seval Turgut is from Elaz $\breve{g}$, Turkey. She received her MS from Firat University in 2019. She is currently at the University of Firat. The author has worked on various projects on building design, building mechanics, strengthening techniques in buildings, blasting and impact. She is currently active in both the market and academic studies.

Dursun Bakır was born in Elazğ, Turkey in 1989. He received his Bs from Firat University in 2012, his MS from Firat University in 2017. He is currently $\mathrm{PhD}$ research fellow at University of Firat. The author continues his doctoral studies on the design and optimum solutions of structures exposed to explosion and impact loads. 